\title{
Health status evaluation of type 2 diabetes patients from two hospitals of northern Peru
}

\section{Evaluación del estado de salud en pacientes con diabetes tipo 2 de dos hospitales del norte del Perú}

\section{$\mathrm{DOI}$}

https://doi.org/10.35434/rcmhnaaa.2021.143.1254

\section{ABSTRACT}

Objetive: To describe illness related knowledge features, mental health, adherence to therapy and quality of life on type 2 diabetes patients from two hospitals from northern Peru. Material and Methods: Cross sectional descriptive study. A cense was made. Descriptive statistics and exploratory analysis were employed. Results: there were 382 diabetes patients: 289 in Lambayeque and 93 in Piura: 112 people were interviewed. The mean age was $59.5+/-11.6$ years, $58 \%$ were women, $59 \%$ were from Piura, $43.8 \%$ only had primary school and $41.5 \%$ referred 2 to 4 outpatient evaluations in the last two years; $28.6 \%$ reported to have been infected by COVID-19: $35,5 \%$ in Lambayeque and $23.8 \%$ in Piura; $17.8 \%$ had poor knowledge about the disease. About mental health, $91.9 \%$ had Depression, $75 \%$ Anxiety and $72.8 \%$, both; $50.6 \%$ had adequate adherence to therapy. The median of quality of life was 161.5 (IQR=127.1-215) and $24.1 \%$ had poor quality of life. In descending order, the more affected dimensions of quality of life were: "control of diabetes", "energy and mobility", "social burden", "anxiety" and "sexual performance". In the exploratory multivariate analysis, depression was associated with high quality of life. Conclusion: disease related-knowledge features, mental health, adherence to therapy and quality of life were poor on type 2 diabetics from these two northern cities of Peru. There were no association between sociodemographic characteristics, mental health, knowledge, adherence, with quality of life.

Keywords: Diabetes, knowledge, quality of life, depression, anxiety (Source: DeCS-BIREME).

\section{RESUMEN}

Objetivo: Describir el conocimiento relacionado con la enfermedad, la salud mental, la adherencia a la terapia y la calidad de vida en pacientes con diabetes tipo 2 de dos hospitales del norte de Perú. Material y Métodos: estudio descriptivo transversal. Se hizo un censo. Se empleó estadística descriptiva y análisis exploratorio. Resultados: hubo 382 pacientes con diabetes: 289 de Lambayeque y 93 de Piura: se entrevistaron 112 personas. La edad promedio fue de 59,5 +/- 11,6 años, 58\% eran mujeres, $59 \%$ de Piura, $43,8 \%$ solo tenían primaria y $41,5 \%$ refirieron 2 a 4 evaluaciones por consulta externa en los últimos dos años; $28,6 \%$ reportó haber tenido COVID-19: $35,5 \%$ en Lambayeque y $23,8 \%$ en Piura; en $17,8 \%$ el conocimiento sobre su enfermedad fue deficiente; $91,9 \%$ tenía depresión, $75 \%$ ansiedad y $72,8 \%$, ambos; $50,6 \%$ tuvo una adecuada adherencia a la terapia farmacológica. La Franco León-Jiménez ${ }^{1,2, a}$, Daysi Barreto-Pérez ${ }^{3,4, b}$, Lida Altamirano-
Cardozo $^{3, c}$, Blanca Loayza-Enríquez
FILIATION

1. Hospital Santa Rosa. Piura, Perú.

Center for Global Health, Universidad Peruana Cayetano Heredia. Tumbes, Perú.

Hospital Regional Lambayeque. Chiclayo, Perú.

Facultad de Medicina Humana, Universidad de San Martín de Porres, Chiclayo, Perú.

Internal Medicine Physician.

Nutritionist.

d. Endocrinologist, Hospital Santa Rosa, Piura.

ORCID

1. Franco León-Jiménez / 0000-0002-9418-3236

3. Lida Altamirano-Cardozo / 0000-0001-7167-8036

5. Juanita Farfán-García / 0000-0003-2792-3107

2. Daysi Barreto-Pérez / 0000-0002-0073-5758 4. Blanca Loayza-Enríquez / 0000-0002-2541-3149

CORRESPONDENCE

Franco León-Jiménez

EMAIL

francoernestole@gmail.com

CONFLICTS OF INTEREST

The authors declare not having conflicts of interest.

FINANCING

Self-financed.

\section{ETHICS APPROVALAND CONSENT TO PARTICIPATE} The project was approved by Hospital 1 Investigation Ethics' Committee (Code: $0222-032-20 \mathrm{CEI})$. An informed
consent was obtained of each patient; a format was handed; each patient received information about the project's consent was obtained of each patient; a format was handed; each patient received information
objectives, information's confidentiality aspects, participation benefits and free evaluation.

\section{CONSENT FOR PUBLICATION}

All participants were requested authorization to publish the results. In case of depression/anxiety, a visit to a mental health specialist was suggested. A copy of the report was delivered to every diabetes strategy. All methods employed were carried out in accordance
with current guidelines and regulations.

\section{AVAILABILITY OF DATAAND MATERIALS}

The dataset supporting the conclusions of this article is available as an additional file.

\section{AUTHORS' CONTRIBUTIONS}

FLJ: Elaborated the protocol, analyzed the information and wrote the article

LAC: Elaborated the protocol, reviewed the last version and approved the final version

BLE: Elaborated the protocol, reviewed the last version and approved the final version DBP: Elaborated the protocol, reviewed the last version and approved the final version JFG: Elaborated the protocol, reviewed the last version and approved the final version

\section{ACKNOWLEDGEMENTS}

To the authorities of each hospital for authorizing the development of this investigation

REVISIÓN DE PARES

Recibido: $17 / 05 / 2021$

COMO CITAR

León-Jiménez, F., Barreto-Pérez, D., Altamirano-Cardozo, L., Loayza-Enríquez, B., \& Farfán-García, J. Evaluación del estado de salud en pacientes con diabetes tipo 2 de dos hospitales del norte del Perú. Revista Del Cuerpo Médico Hospital Nacional Almanzor Aguinaga Asenjo, 2021, 14(3). https:// doi.org/10.35434/rcmhnaaa.2021.143.1254 
mediana de calidad de vida fue 161,5 (RIC $=127,1-215$ ) y en $24,1 \%$ la calidad de vida fue deficiente. En orden descendente, las dimensiones de la calidad de vida más afectadas fueron: "control de la diabetes", "energía y movilidad", "carga social", "ansiedad" y "desempeño sexual". En el análisis exploratorio multivariado, la depresión se asoció con una alta calidad de vida. Conclusión: el conocimiento relacionado con la enfermedad, la salud mental, la adherencia a la terapia y la calidad de vida fueron deficientes en los diabéticos tipo 2 de estas dos ciudades del norte del Perú. No hubo asociación entre características sociodemográficas, salud mental, conocimientos, adherencia y calidad de vida.

Palabras Clave: Diabetes, conocimiento, calidad de vida, depresión, ansiedad. (Fuente: DeCS-BIREME).

\section{INTRODUCTION}

Type 2 Diabetes (T2D) continues to be a public health matter. It causes handicap as well as high disease costs and burden. On the world, there are more than 463 millions of people living with it (prevalence $=9.3 \%$ ). It has a prevalence of $9.4 \%$ in Latin America and $22.7 \%$ in older than 65 years; more than $80 \%$ of deaths from diabetes occur in low and middle-income countries $^{(1)}$. The PERUDIAB 2012 study conducted in 1,677 homes nationwide, representative of more than 10 million adults over 25 years of age, has found a $7 \%$ prevalence of DBT in Peru, highest in the coast: $8.2 \%^{(2)}$. Piura and Lambayeque are two important cities from the northern coast of Peru with $2^{\prime} 047,954$ and 1,310,785 people, respectively ${ }^{(3)}$.

In the other hand, T2D is a complex disease; its treatment and focus require a holistic model called Chronic Care Model (CCM). Proactive and multidisciplinary work, self-care support, adequate use of evidence-based medicine, information systems for healthcare staff and policies to ensure life-style changes and equity in the healthcare system are the bases ${ }^{(4)}$. This model has proven to diminish cardiovascular complications and resulting mortality in a systematic review ${ }^{(5)}$.

On the other side, ADA (American Diabetes Association) guidelines propose the High-Quality Diabetes SelfManagement Education and Support (DSMES) as a measure to improve glycemic control, patient's satisfaction and diabetes self-management. This consists in the patient acquiring knowledge, abilities, decision making and problem-solving skills; and its founded on a multi-disciplinary team presence $^{(6)}$. Thus, an integral focus on the patient is important.

Also, mental health problems like anxiety and depression frequently co-exist with diabetes; they must be screened, diagnosed and treated in order to improve treatment adherence. $\mathrm{Li}$, in 2006, found in 20,142 diabetics that anxiety life prevalence was $19,5 \%$, being superior in Hispanics ${ }^{(7)}$; not reaching glycemic objectives and insulin use have been listed as triggers. ADA suggests an annual depression screening, especially when therapeutic shifts or cardiovascular complications occur ${ }^{(8)}$. Depression treatment can improve glycemic control. Moreover, an adequate treatment adherence, proper knowledge regarding their illness and to consider the patient's life quality are CCM and DSMES focuses' pillars, proposed by ADA.

It is true the budget per results strategy rules locally and nationally, and since the chronic non-transmittable diseases' strategy gathers a larger number of patients, said patients management tends to be inefficient and fragmented. The strategy contemplates educational tactics as well as a team conformed by different healthcare professionals, but there isn't an articulation of sorts nor leadership when it comes to its implementation or when measuring its effectivity in the local context. The lack of local data, the improvement opportunities with a better data management and favorable results in other systems as evidence contributes to the need for generating information. This study will allow to, initially, characterize diabetes patients from two great hospitals in the northern macrorregión's health status and manage their healthcare according to their data. The study's objective was to describe the health status of DBT patients from two hospitals in northern Peru during 2020.

\section{MATERIALAND METHODS}

Cross sectional descriptive study. Population consisted of patients attended by the chronic non-transmittable diseases' strategy from two peruvian hospitals of the Ministry of Health (MINSA): Regional Lambayeque, high complexity (Hospital 1), and Santa Rosa de Piura, medium complexity (Hospital 2); both of them are the most complex in their regions; statistical records from both hospitals show, the number of diabetics during 2018, was 1735 at Hospital 1 and 386 at Hospital 2; considerating an adequate Diabetes knowledge frequency of $38 \%$ (previous study held at Hospital 1) ${ }^{(9)}, 95 \%$ confidence level, $5 \%$ significance level, the expected sample size was 326: 260 at Hospital 1 and 66 at Hospital 2. Nevertheless, in the diabetes strategy databank, only 280 phone numbers were registered at Hospital 1 and 93 at 2, so a census was held. Figure 1 depicts the participant selection process. For this study, "health status" was assigned to the following variables' descriptions: Diabetes Knowledge, Anxiety/Depression presence, Diabetes-related Quality of Life, and pharmacological treatment adherence.

Diabetes knowledge: A previously validated questionnaire at Hospital 1, was employed, consisting of 17 questions, a 0.76 Cronbach's alpha, categories being: Low (less than 50 percentile), moderate (p50-p75) and high (>p75) ${ }^{(9)}$.

Depression and Anxiety: Beck's inventories for each condition, validated in our country, were used ${ }^{(10)}$. The depression one was validated in general medicine patients, with a 0,889 Cronbach's alpha, and has a Kaiser-Meyer-Olkin $(\mathrm{KMO}=0.95)$ and a Bartlett's sphericity test $(\mathrm{chi} 2=3603.2, \mathrm{p}$ $<.001)$ for factorial analysis ${ }^{(11)}$. Both inventories classified each patient with absent, low, moderate or severe depression; these inventories have been previously used by the author on diabetics at external consult in Lambayeque $^{(12,13)}$.

Treatment adherence: The Moriski Green questionnaire ${ }^{(14)}$ was used;previously used in patients with $\mathrm{DBT}^{(15)}$ and in a study in patients from Lambayeque ${ }^{(16)}$. It has a Cronbach's 
alpha of $0.61 ; 94 \%$ specificity and $91.6 \%$ positive predictive value.

Diabetes-related quality of life: The Diabetes 39 Spanish questionnaire, validated in México in 260 Type 2 patients with diabetes, was applied. It has 0,95 Crombach's alpha, and a test $r$ upper than 0,7 with 39 items organized in 5 dimentions: Energy-Mobility:15 items, Diabetes control: 12 items; Anxiety: 4 items, social charge: 4 items and sexual function: 5 items ${ }^{(17)}$. For the purpose of this investigation, percentiles 25th, 50th and 75th were calculated to describe low, moderate, high and very high quality of life. To explore association between quality of life and the other variables, the 50th percentile divided low and high quality of life.

\section{Analysis}

Of both diabetes strategies registers, patient's lists were solicited in order to obtain phone numbers and addresses; the dates and hours were settled with the patient/caretaker; 2 interviewers at Lambayeque and 1 at Piura carried out the visits, with personal protection equipment at all times. For numeric variables; means, standard deviations, medians and interquartile ranks were calculated. To explore association between categorical variables, $\mathrm{X} 2$ was employed and between numeric variables, student's $T$ or Wilcoxon according to the variable's normality. The principal variable in the study was Quality of Life, so, an an association between other variables and this one was explored.To explore association between quality of life and the other variables, the 50th percentile divided low and high quality of life (HQL). First an exploratory bivariate analysis was made between $\mathrm{HQL}$ and socio-demographic, level of knowledge, adherence, Depression and Anxiety. The variables that in the bivariate analysis show a "p" value of 0.05 or less, were included in the multivariate logistic regression analysis. Stata 15 was used for data analysis.

\section{Ethical aspects}

\section{Ethics approval and consent to participate}

The project was approved by Hospital 1 Investigation ethics' Committee (Code: 0222-032-20 CEI). An informed consent was obtained of each patient; a format was handed; each patient received information about the project's objectives, information's confidentiality aspects, participation benefits and free evaluation.

\section{Consent for publication}

All participants were requested authorization to publish the results. In case of depression/anxiety, a visit to a mental health specialist was suggested.

A copy of the report was delivered to every diabetes strategy. All methods employed were carried out in accordance with current guidelines and regulations.

\section{RESULTS}

In both hospitals, at the beginning of 2020, there were 382 diabetes patients: 289 in Lambayeque and 93 in Piura. Patient recruitment process is shown in figure 1.

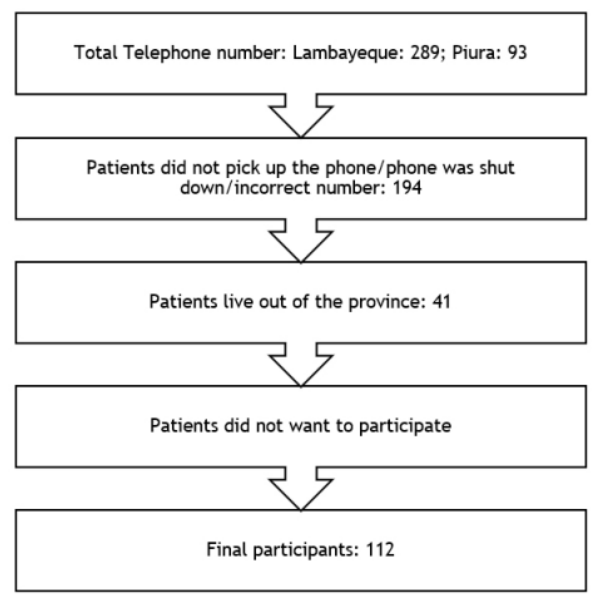

Figure 1.

Patient uptake flow chart

Nine patients $(2,35 \%)$ passed away, all of them from Lambayeque; $41 / 382(10,7 \%)$, were living in another province, all of them from Lambayeque. In Lambayeque, $170 / 289(58,8 \%)$ patients, didn't pick up the phone or the phone was shut down or the telephone number was incorrect, and in Piura: 24/93 (25,8\%). Were interviewed 112 participants $(29,3 \%)$. The mean age was $59.5+/-11.6$ years, with a normal distribution (Shapiro-Wilk $=0.4$ ); $58 \%$ were women, $59 \%$ were from Piura, $43.8 \%$ only elementary school, $41.5 \%$ referred that had had $2-4$ outpatient evaluation in the last two years; $36.6 \%$ mentioned that had been hospitalized due to DBT in the last 2 years. The more frequent medical history was high blood pressure: 55/112 (49.2\%). Other results appear in table 1.

Table 1. General characteristics of the participants.

\begin{tabular}{lcc} 
& Median & ICR \\
\hline Age & 60 & $50.5-82$ \\
Years living with Diabetes & 8 & $3-35$ \\
& $\mathrm{~N}$ & $\%$ \\
Female & 65 & 58.04 \\
Region of origin & & \\
$\quad$ Piura & 67 & 59.8 \\
Lambayeque & 45 & 41.2 \\
Level of education & & \\
Illiterate & 6 & 5.3 \\
Elementary & 49 & 43.8 \\
High School & 47 & 41.9 \\
Technical/Higher Education & 10 & 8.4 \\
Health Personnel & 4 & 3.6 \\
Outpatient care & & \\
2-4 times & 46 & 41.5 \\
4-6 times & 21 & 18.9 \\
6-8 times & 13 & 11.7 \\
More than eight & 31 & 27.9 \\
Educational talks & 40 & 35.7 \\
Diabetes in the family & 65 & 58 \\
Hospitalized due to DBT & 41 & 36.6 \\
Cerebrovascular Disease & 3 & 2.7 \\
High blood pressure & 55 & 49.2 \\
Renal chronic disease & 16 & 14.3 \\
\hline
\end{tabular}


In Piura, 29/66 (43.6\%) patients had more than 8 outpatient controls and in Lambayeque only $2 / 45(4.4 \%), p<0,001$. There were not differences in sociodemographic variables quality of life, mental health, adherence and knowledges about DBT2 between the two cities. Glycemia value was present only in 64/112 (57.14\%); the median was: 137 (IQR= 113-350) and glycated Hemoglobin was present in only 20/112 (17,8\%). The median was: $8.6($ IQR= 6.7-12.9).

In disease-related knowledge, $93.7 \%, 89.3 \%$ and $88.3 \%$ mentioned that "Diabetes should be treated forever", it "cannot be cured" and that "it is possible to control it". On the other hand, only $38.4 \%, 32.4 \%$ and $16.9 \%$, knew the "blood glucose value that define Diabetes", "the way to cut toenails" and that a patient with diabetes "could consume condiments in meals". Table 2.

Table 2. Distribution of the frequency of disease-related knowledge.

\begin{tabular}{llc}
\multicolumn{1}{c}{ Questions } & $\mathrm{N}$ & $\%$ \\
\hline Knowledge about Diabetes should be treated forever & 105 & 93.7 \\
Can Diabetes de cured? & 100 & 89.3 \\
Is it possible to control diabetes? & 99 & 88.3 \\
Reason for taking care of feet & 97 & 87.4 \\
Symptoms of hypoglycemia & 96 & 85.7 \\
Definition of Diabetes & 95 & 84.8 \\
Causes of Diabetes decompensation & 91 & 81.2 \\
Organs that can be damaged without treatment & 83 & 74.8 \\
Chronic use of Insulin at home & 81 & 72.9 \\
Correct name of their disease & 80 & 71.4 \\
Managing healthy lifestyles & 77 & 68.8 \\
Consumption of fried foods at meals & 72 & 64.3 \\
Minutes per day of physical activity & 66 & 58.9 \\
Footwear characteristics & 64 & 57.7 \\
Amount of sweet in meals & 61 & 54.5 \\
Ideal glycemic value a diabetic patient should have & 57 & 50.9 \\
Organs damaged by poor glycemic control & 56 & 50.5 \\
Main symptoms of decompensated diabetes & 55 & 49.1 \\
Blood glucose value that define Diabetes & 43 & 38.4 \\
Way to cut toenails & 36 & 32.4 \\
Consumption of condiments in meals & 19 & 16.9 \\
\hline
\end{tabular}

The 25th, 50th and 75th percentiles of the questionnaire were: 12,14 and 19 , respectively; $44.6 \%$ had moderate level of knowledge. Only $37.46 \%$ had very high/high knowledge about their disease.

About mental health, $103 / 112(91.96 \%)$ had Depression, 84/112 (75\%) Anxiety and both: 75/112 (72.82\%); 82/112 (73.21\%) had severe depression and 16/112 (14.29\%) severe anxiety; only $45 / 89$ (50.6\%) had adequate medication adherence.

The median of the quality of life was: $161.5($ IQR=127.15-215) and $24.1 \%$ had poor quality of life. Table 3.
Table 3. Health status in the total of participants.

\begin{tabular}{lcc} 
DBT knowledge & N & $\%$ \\
\hline Very high & 5 & 4.46 \\
High & 37 & 33 \\
Moderate & 50 & 44.6 \\
Low & 20 & 17.8 \\
\hline Depression & & \\
\hline Absence & 9 & 8.04 \\
Low & 8 & 7.14 \\
Moderate & 13 & 11.61 \\
Severe & 82 & 73.21 \\
Anxiety & & \\
\hline Absence & 28 & 25 \\
Low & 44 & 39.29 \\
Moderate & 20 & 17.86 \\
Severe & 20 & 17.86 \\
Adherence & 45 & 50.6 \\
Quality of Life & & 24.1 \\
\hline High & 29 & 25.9 \\
Moderate & 56 & 50 \\
Poor & 27 & \\
\hline
\end{tabular}

In table 4 appear the median and IQR of the dimensions of the scale.

Table 4. Diabetes 39 Quality of life Items.

\begin{tabular}{lcc} 
& Median & IQR \\
Diabetes control & 51.5 & $43-65$ \\
Anxiety and Concern & 15 & $15-24$ \\
Social burden & 19 & $13-29$ \\
Sexual performance & 11 & $7-19$ \\
Energy and mobility & 61 & $49.5-85$ \\
Quality of life & 4 & $3.5-7$ \\
DBT severity & 5 & $4-7$ \\
\hline
\end{tabular}

When we corrected the value taking into account the number of items of each dimensions, we obtained that in descending order, the more affected were: "Diabetes control", then, "energy and mobility", "Social burden", "anxiety and concern" and finally, "sexual performance".

Referred to have been infected by COVID-19: $32 / 112$ (28,6\%): $16 / 45(35,5 \%)$ in Lambayeque and $16 / 67(23,8 \%)$ in Piura; only one patient from Piura had severe COVID-19 and was hospitalized.

There were no differences in age: $60.2+/-11.3$ vs $58.9+/-12$ $(p=0.596)$ and years with Diabetes: $10.1+/-9.6$ vs $11.5+/-$ $8.8(p=0.59)$, between patients with and without HQL. Also there were not differences in $\mathrm{HQL}$ between female and males: $53.85 \%$ vs $44.68 \%(p=0.222$ ), city of origin: $55.22 \%$ in Piura vs $42.22 \%$ in Lambayeque $(p=0.124)$, scholarship: $56 \%$ in those with complete high school/ technical/university studies vs $48.28 \%$ in those with incomplete high school/elementary or illiterate $(p=0.325)$, outpatient visits in the last two years: $51.11 \%$ in those with more than 2 and $49.25 \%$ in the others $(p=0.500)$, having received educational 
talks: $45 \%$ in those who received vs $52.78 \%$ in the others $(p=$ 0.277 ), have high blood pressure: $49 \%$ in those with and $50.88 \%$ in the others $(p=0.500)$, have Chronic Renal disease: $56.5 \%$ in patients with vs $48.96 \%$ in those without $(p=0.394)$; HQL was present in $63 \%$ of patients previously hospitalized due to DBT2 and in $42.25 \%$ of whom have never been hospitalized $(p=0.049)$.

There were not association between level of knowledge $(p=$ $0.17)$, nor medication adherence $(p=0.453)$ with HQL; HQL was present in $68.57 \%$ of patients with Depression and in $19 \%$ in those without it $(\mathrm{p}<0.0001)$ and in $47.62 \%$ of patients with anxiety and $87.52 \%$ without it $(\mathrm{p}=0.057)$.

When we considered the quality of life as a number, there were no differences of the means of quality of life between patients with or without Depression $(150.79+/-38.65$ vs $170.22+/-12.3, p=0.125)$.

The mean of the score of quality of life was higher in patients with anxiety $(162+/-32.69$ vs $123.17+/-36.66, p=0,0001)$. In the exploratory multivariate analysis, (with quality of life as a dichotomous variable) only the presence of Depression was associated with HQL $(P=0,0001)$. Table 5.

Table 5. Exploratory Multivariate analysis with High Quality of Life.

\begin{tabular}{lccc} 
Characteristic & PR & Cl 95\% & P \\
Depression & 8.5 & $3.3-22$ & 0.00 \\
Anxiety & 0.19 & $0.02-1.82$ & 0.152 \\
Hospitalized due to DBT & 2.23 & $0.91-5.50$ & 0.079 \\
\hline
\end{tabular}

$P R=$ Prevalence Ratio; Cl: Confidence interval

\section{DISCUSSION}

Pandemic has modified patient's tracking and control from health strategies ${ }^{(18)}$; the lack of outpatient attendance for chronic patients may have dilapidated their health. Its investigation is urgent.

It caught our attention the high "wrong telephone number" frequency, especially at Lambayeque; it could be attributed to a lousy valid data management resulting in a poor patient control. Lambayeque's Hospital was designed to gather the northern macro region demand, but has attended, at least before the pandemic, medium complexity pathologies. Moreover, it doesn't have an adjunct population like the Hospital of Piura, which could make data management a smoother process even with low budget. That suggests an exhaustive review of MINSA's Resolution N: 117-2020, related to telemedicine in pandemic times ${ }^{(19)}$.

Low participation frequency $(28,7 \%)$, which is usual on population studies, is vastly notorious. Infection fear with COVID-19 is a possibility. The possible higher complexity of its patients could explain the significant difference in mortality and in foreign patients.

A concept called "health literacy" entails people's knowledge, competences and motivation to understand and apply health information to take decisions for healthcare to improve quality of life and get a better health status. In this study, we did not measure this, but knowledge is an important issue of it; $17.8 \%$ had poor knowledge about the disease and $37.4 \%$ high/very high knowledge. Abdullah in a systematic review of twenty-nine studies involving 13,457 patients with T2DM from seven countries, found that the prevalence of limited health literacy ranged from $7.3 \%$ to $82 \%$, lowest in Switzerland and highest in Taiwan. In USA was $28.9 \%$ and $26-45 \%$ in Brazil. Although it is true these aren't the same concepts and that the instruments used were different, the findings area similar ${ }^{(20)}$. It could suggest that people living with diabetes in these two cities may have an acceptable level of knowledge about their disease. It is a matter of future investigations. Also, health literacy is related to knowledge ${ }^{(21)}$, and to treatment adherence ${ }^{(22)}$.

It seems as patients were informed about theory aspects of T2DM: it can' $t$ be cured, it can be control. But some practice aspects such as: how to take care of their feet $(57,7 \%$ and $32,2 \%$ of correct answers in both items) and characteristics of diet (fried foods: $64.3 \%$, sweet meals: $54.5 \%$ and condiments in meals: $16.9 \%$ ) didn't reach a high frequency of correct answers. This could tell us adequate practices are scarce. Nevertheless, they should be measured. Practices are much more difficult to test and must be measure in situ.

About mental health, $91.96 \%$ had Depression (severe in $73.2 \%$ ) and $75 \%$ had Anxiety. About Depression, Anderson during 2001 in a systematic review, found that people with T2DM had double risk of having Depression when they were compared with general population ${ }^{(23)}$. There is a bidirectional influence between these two health problems. Patients with both, have poorer quality of life, diminished self-care and more risk of hyperglycemia ${ }^{(24)}$. Also micro and macrovascular complications are more frequent with increases in mortality ${ }^{(25,26)}$. Nevertheless, in the multivariate analysis, we have found an association between High quality of Life and Depression. There are some probable explanations for it: first, the questionnaire "Diabetes-related quality of life" has been validated to be qualified as a number. For the purpose of exploring association in this study, we also considered the quality of life as a dichotomous variable. Other possibility could be the simple size. When we considered quality of life as a number there were no differences.

Amiri in 2019, in an systematic review of 23 studies, found that pooled odds ratio was: $1.48 ;(\mathrm{Cl} 95 \%=1.27-1.74)$; when considering only cross-sectional studies, the odds were= 1.50; $(\mathrm{Cl} 95 \%=1.26-1.77$, and in prospective-cohort studies, $1.34(\mathrm{Cl} 95 \%=1.21-1.49)$. In all the observational designs, Diabetes was an independent factor to develop anxiety ${ }^{(27)}$. On the other hand, Smith in 2018, in another systematic review of prospective studies demonstrated patients with anxiety also were at more risk to develop T2DM. In total, 14 studies (n $=1^{\prime} 760,800$ ) examined anxiety as a risk factor for incident diabetes. The odds ratio found was $1.47(\mathrm{Cl}=1.23-1.75)^{(28)}$.

Constantino, during 2014 in Peru, in a national hospital from Lambayeque, found that frequencies of Anxiety and Depression were: $65.2 \%$ and $57.8 \%$, and both: $57.8 \%{ }^{(26)}$. In our study the frequencies are higher (91.96\% Depression) and (75 $\%$ Anxiety); both: $72.82 \%$. In both studies the Beck inventories were applied. It could be explained due to the pandemic. In 
Revista del Cuerpo Médico del HNAAA, Vol 14 (3) - 2021

fact, house confinement, social distancing and fear of getting infected could have altered quality of life and spiked up depression and anxiety rates in this context. Alessi in Brazil, in 120 uncontrolled diabetics with a 21 -year-old disease age and with a referred $42 \%$ of partial house confinement, found $42 \%$ of psychological distress (anxiety/depression symptoms), $29 \%$ of T2DM related emotional distress, $75 \%$ of sleep disorders and $7 \%$ of suicidal ideation ${ }^{(29)}$.

It is very important to consider the high frequency of both depression and anxiety to support mental health services to help these patients. Actually, we have no data if chronic noncommunicable disease strategy in both hospitals, is supporting mental health strategies to assist their patients. It is a matter that should be investigated and an institutional commitment.

Unfortunately, the problems founded in the laboratory registries didn't let us establish if there was an adequate glycemic control. Constantino in the study mentioned, didn ' $t$ find association between glycemic control and depression (PR $=0.94,95 \% \mathrm{Cl} 0.83-1.07, \mathrm{p}>0.05)$ and anxiety $(\mathrm{PR}=0.95,95 \%$ $\mathrm{Cl} 0.77-1.16, \mathrm{p}>0.05)^{(30)}$.

One of two patients were no adherent to medical therapy. Iglay in a systematic review during 2015, in 13 studies of T2DM, found that $75.3 \%(\mathrm{Cl}=68.8 \%-81.7 \%)$ had adequate adherence to oral therapy ${ }^{(31)}$.

Carranza, during 2018, in diabetic foot amputees from the Lambayeque hospital, found that $47.3 \%$ were adherent to pharmacological treatment ${ }^{(32)}$. In another study, Villalobos in 2017, in 218 primary care diabetics from Lambayeque, found a pharmacological adherence of $35.8 \%^{(16)}$.

In spite of these, last studies explore adherence in primary care and in people with evident target organ damage, findings are useful to explore the problem. Data suggest that in our region (northern coast of Peru), adherence is poor. Analytic observational studies or qualitative research to explore factors/ Cosmo vision (alcohol use? / beliefs) does not exist in our region and must be done. The worst the adherence, the worst the future of the patients. Telemedicine and supporting of mental health problems could had an impact on this variable.

The median of quality of life was 161.5 (IQR=127.1-215) and $24.1 \%$ had poor quality of life. "Diabetes control", then, "Energy and mobility", were the dimensions more affected. It could be interpreted that patients perceived they can't control their disease and that they have physical limitations to do their activities. The fact that Energy and mobility area is the second affected, could mean that some amputated patients or patients with severe neuropathy have participated. Unfortunately, these variables were not considered. Mokhtari in a systematic review of 17 studies, with a sample size of 5472 patients from Iran, found that the dimension more affected was physical, and general health. These findings are very similar to ours. It could be because of the similarity of the populations. Nevertheless, the instruments used were different. In that study the instruments used were the Health Related quality of life and the SF-36. Their patients showed to have moderate quality of life $^{(30)}$. We found that one of two had moderate quality of life. It could suggest similarities in the populations.

Ozdemir, during 2017, in a cross-sectional study of 150 T2D patients from an endocrinology clinic from Nigeria, found a statistically significant negative correlation between Beck Anxiety Score and the punctuations of the quality of life test $^{(33)}$.

Both, the Chronic Care Model (CCM) ${ }^{(5)}$ and the High-Quality Diabetes Self-Management Education and Support (DSMES) ${ }^{(6)}$ are constructs that are necessary to ensure a holistic care support for T2DM; proactive and multidisciplinary work, self, adequate use of evidence-based medicine, information systems for healthcare staff, policies to ensure life-style changes, equity in the healthcare system and presence of knowledge, abilities, decision-making and problem-solving skills. The results of this study suggests that chronic noncommunicable disease strategies from both cities of northern Peru needs more institutional commitment. There is so much problems to afford and it is time to begin.

On the other hand, this is the first Peruvian study that evaluates the frequency of COVID infection in diabetics from the outpatient attendance: $28,6 \%: 35,5 \%$ in Lambayeque and $23,8 \%$ in Piura. In spite of the possibility it could be an interviewer bias, these numbers could be related to what is happening in the pandemic ${ }^{(34)}$. On January t18th, Lambayeque has 2,609 and Piura 2,169 cases per 100,000 inhabitants, so it could be explained because this numbers. Nevertheless, the data in this study only regards on the information given by people at home.

We must comment only $29.2 \%$ people were surveyed; most telephone numbers were wrong. These results are worrying, since Lambayeque hospital has greater support from the Budget for Results (BFR) initiative of the Economy and Finance Ministry.

These characteristics complicate the picture, a reality that can exacerbate people's health status, due to the late identification of complications and comorbidities. The data management logistics shall be revised through qualitative studies in order to explore the patient and their families' perspective on telemedicine tracking. There is a need for more qualified human resources, since it has an impact on people's health and costs implied with complications.

Among the limitations we should mention the bias associated with transversal studies and the problems of sampling, already mentioned.

Also, we didn't include the HbA1c of all the patients nor the weight, height or blood pressure controls, given the aforementioned restrictions.

Other limitation is that we did not measure if patients had Cardiac Insufficiency, amputations/diabetic foot that could alter these results.

In conclusion, disease-related knowledge features, mental health, adherence to therapy and quality of life were poor on type 2 diabetics from these two northern cities of Peru. There is a very high frequency of both Depression and Anxiety in 
both hospitals.

\section{BIBLIOGRAPHIC REFERENCES}

1. International Diabetes Federation. Atlas de la Diabetes de la FID. A v a i l a ble a t : https://diabetesatlas.org/upload/resources/material/20200302_1 33352_2406-IDF-ATLAS-SPAN-BOOK.pdf. Date of access: 11 January 2021.

2. Seclen SN, Rosas ME, Arias AJ, Huayta E, Medina CA. Prevalence of diabetes and impaired fasting glucose in Peru: report from PERUDIAB, a national urban population-based longitudinal study. BMJ Open Diabetes Res Care. 2015;3(1): e000110. doi:10.1136/bmjdrc-2015000110.

3. Instituto Nacional de estadística e Informática. Estadísticas de p oblación y vivienda. Ava ilable a t : https://www.inei.gob.pe/media/MenuRecursivo/publicaciones_dig itales/Est/Lib1758/cap03/ind03.htm. Date of access: 11 January 2021.

4. Jing-Xia Kong, Lin Zhu, Hong-Mei Wang, Ying Li, An-Ying Guo, Chao Gao, Yan-Yao Miao, Ting Wang, Xiao-Yang Lu, Hong-Hong Zhu, Donald L. Patrick, "Effectiveness of the Chronic Care Model in Type 2 Diabetes Management in a Community Health Service Center in China: A Group Randomized Experimental Study", Journal of Diabetes Research, vol. 2019 , Article I D 6516581,12 page s. https://doi.org/10.1155/2019/6516581

5. Wan EYF. Fung CSC, Jiao FF, Yu EYT, Chin WY, Fong DYT, Wong CKH, Chan AKC, Chan KHY, Kwok RLP, Lam CLK. Five-Year Effectiveness of the Multidisciplinary Risk Assessment and Management Programme-Diabetes Mellitus (RAMP-DM) on Diabetes-Related Complications and Health Service UsesdA Population-Based and Propensity Matched Cohort Study. Diabetes Care 2018; 41:49-59.

6. American Diabetes association. Standards of medical care in Diabetes 2020 . A v a i l a b l e a t : https://care.diabetesjournals.org/content/diacare/suppl/2019/12 I20/43.Supplement_1.DC1/DC_43_S1_2020.pdf. Date of access: 06 January 2020.

7. Li C, Barker L, Ford ES, Zhang X, Strine TW, Mokdad AH. Diabetes and anxiety in US adults: findings from the 2006 Behavioral Risk Factor Surveillance System. Diabet Med 2008; 25:878-88.

8. Katon WJ, Von Korff M, Lin EHB, Simon G, Ludman E, Russo J, Ciechanowski P, Walker E, Bush T. The Pathways Study: a randomized trial of collaborative care in patients with diabetes and depression. Arch Gen Psychiatry 2004; 61: 1042-1049.

9. Chunga- Aparicio $M$, Vásquez-Rojas $C$, Jiménez-León $F$, Díaz-Vélez C, Sifuentes J, Osada Liy J. Validación de un instrumento para medir conocimientos sobre su enfermedad en pacientes diabéticos de dos hospitales de Lambayeque. Available at: http://www.rem.hrlamb.gob.pe/index.php/rem/article/view/104 190. Date of access: 27 January 2020.

10. Vega-Dienstmaier J, Coronado-Molina O, Mazzotti G. Validez de una versión en español del Inventario de Depresión de Beck en pacientes hospitalizados de medicina general. Rev Neuropsiquiatr. 2014, 77 (2), 95-103.

11. Lustman PJ, Clouse RE, Griffith LS, Carney RM, Freedland KE. Screening for depression in diabetes using the Beck Depression Inventory. Psychosom Med. 1997; 59:24-31.

12. Sánchez-Pachas D. Propiedades Psicométricas del Inventario de Depresión de Beckll (IDB-II) en una muestra clínica. Revista de Investigación en Psicología Vol. 22 - N. ${ }^{\circ} 1$ - 2019, pp. 39 - 52

13. Sanz J, García-Vera M, Fortún M. el "Inventario de Ansiedad de Beck” (BAI): propiedades psicométricas de la versión española. Behavioral Psychology / Psicología Conductual, Vol. 20, №3, 2012, pp. 563-583.

14. Val Jiménez A, Amorós Ballestero G, Martínez P, Fernández ML, León M. Estudio descriptivo del cumplimiento del tratamiento farmacológico antihipertensivo y validación del test de Morisky y Green. Aten Primaria. 1992;10:767-70.

15. David M. Mosen, PhD, MPH; Harry Glauber, MB, BCh; Ashley B. Stoneburner, MPH; and Adrianne C. Feldstein, MD, MS. Assessing the Association Between Medication Adherence and Glycemic Control. Am J Pharm Benefits. 2017;9(3):82-88

16. Villalobos C, Villalobos M. Tesis para optar el grado de Bachiller en medicina. Características de la adherencia farmacológica en diabéticos de tres centros de salud de atención primaria Chiclayo 2017 . A v a i l a ble $\quad \mathrm{a} \mathrm{t}$ : http://tesis.usat.edu.pe/bitstream/20.500.12423/1667/1/TL Villa lobosCarlosPercy_VillalobosRiosMargarita.pdf. Date of access: 26 January 2020.

17. López-Carmona J, Rodríguez-Moctezuma R. Adaptación y validación del instrumento de calidad de vida Diabetes 39 en pacientes mexicanos con diabetes mellitus tipo 2. Salud pública de México / vol.48, no.3, mayo-junio de 2006. 200-211.

18. Peric S, Stulnig TM. Diabetes and COVID-19: Disease-ManagementPeople. Wien Klin Wochenschr. 2020 Jul;132(13-14):356-361.

19. Ministerio de Salud. Directiva Administrativa No 285 MINSA/2020/DIGTEL para la implementación y Desarrollo de los servicios de Telemedicina síncrona y asíncrona. Available at: https://cdn.www.gob.pe/uploads/document/file/572011/Resoluci o\%CC\%81n_Ministerial_N_117-2020-MINSA.PDF. Date of access: 15 November, 2020.

20. Abdullah A, Liew SM, Salim H, Ng CJ, Chinna K. Prevalence of limited health literacy among patients with type 2 diabetes mellitus: A systematic review. PLoS One. 2019 May 7;14(5).

21. Powell CK, Hill EG, Clancy DE. The relationship between health literacy and diabetes knowledge and readiness to take health actions. Diabetes Educ. 2007;33: 144-151.

22. Osborn CY, Cavanaugh K, Wallston KA, Kripalani S, Elasy TA, Rothman $\mathrm{RL}$, et al. Health literacy explains racial disparities in diabetes medication adherence. J Health Commun. 2011;16: 268-278.

23. Anderson, R. J., Freedland, K. E., Clouse, R. E. \& Lustman, P. J. Te prevalence of comorbid depression in adults with diabetes: a metaanalysis. Diabetes Care. 2001; 24, 1069-1078.

24. Semenkovich K, Brown ME, Svrakic DM, Lustman PJ. Depression in type 2 diabetes mellitus: prevalence, impact, and treatment. Drugs 2015; Apr;75(6):577-87. doi: 10.1007/s40265-015-0347-4. PMID: 25851098.

25. Lustman PJ, Anderson RJ, Freedland KE, de Groot M, Carney RM, Clouse RE. Depression and poor glycemic control: a meta-analytic review of the literature. Diabetes Care. 2000;23(7):934-42. 46.

26. De Groot M, Anderson R, Freedland KE, Clouse RE, Lustman PJ. Association of depression and diabetes complications: a metaanalysis. Psychosom Med. 2001;63:619-30

27. Amiri S, Behnezhad S. Diabetes and anxiety symptoms: A systematic review and meta-analysis. Int J Psychiatry Med. $2019 \mathrm{Apr}$ 2:91217419837407. doi: 10.1177/0091217419837407.

28. Smith KJ, Deschênes SS, Schmitz N. Investigating the longitudinal association between diabetes and anxiety: a systematic review and meta-analysis. Diabet Med. 2018 Jun;35(6):677-693.

29. Constantino-Cerna Antero, Bocanegra-Malca Milagros, León-Jiménez Franco, Díaz-Vélez Cristian. Frecuencia de depresión y ansiedad en pacientes con diabetes tipo 2 atendidos en un hospital general de Chiclayo. Rev Med Hered. 2014 ( 4 ): 196-203.

30. Alessi J, de Oliveira GB, Franco DW, Brino do Amaral B, Becker AS, Knijnik CP, Kobe GL, de Carvalho TR, Telo GH, Schaan BD, Telo GH Mental health in the era of COVID-19: prevalence of psychiatric disorders in a cohort of patients with type 1 and type 2 diabetes during the social distancing. Diabetol Metab Syndr. 2020 Aug $31 ; 12: 76$.

31. Iglay K, Cartier SE, Rosen VM, Zarotsky V, Rajpathak SN, Radican L, Tunceli K. Meta-analysis of studies examining medication adherence, persistence, and discontinuation of oral antihyperglycemic agents in type 2 diabetes. Curr Med Res Opin. 2015;31(7):1283-96.

32. K. Carranza Carranza, A. Grosso Salazar, F. León Jiménez, F. Amaro Martin, Evaluación del estado de salud en pacientes amputados por pie diabético de dos hospitales del Perú en 2017. Rehabilitación 2019; Volume 53, Issue 2, 78-84.

33. Mokhtari Z, Gheshlagh RG, Kurdi A. Health-related quality of life in Iranian patients with type 2 diabetes: An updated meta-analysis. Diabetes Metab Syndr. 2019 Jan-Feb;13(1):402-407.

34. Ozdemir N, Sahin AZ. Anxiety levels, quality of life and related sociodemographic factors in patients with type 2 diabetes. Niger J Clin Pract. 2020 Jun;23(6) 19.

35. Ministerio de Salud. Sala Situacional Covid-19 Perú. Available at: https://covid19.minsa.gob.pe/sala_situacional.asp. Date of Access: January 19, 2021. 